JKM (Jurnal Kebidanan Malahayati),Vol 7,No.3.Juli 2021,

ISSN (Print) 2476-8944 ISSN (Online) 2579-762X, Hal 421-425

\title{
HUBUNGAN ANTARA KREDIBILTAS KADER DENGAN TINGKAT KUNJUNGAN DI POSYANDU
}

\author{
Didah $^{1}$, Sri Astuti ${ }^{2}$, Arfina $^{3}$ \\ 1-2Departemen IImu Kesehatan Masyarakat Fakultas Kedokteran Universitas Padjadjaran \\ 3Prodi D4 Kebidanan FK Unpad \\ Email : didah@unpad.ac.id
}

\section{ABSTRACT THE CORRELATION BETWEEN THE CREDIBILITY OF CADRES WITH A RATE OF VISITS IN POSYANDU.}

Background : Posyandu (Integrated Service Post in Indonesian) activities are highly dependent on its cadre, in which they play a pivotal role in helping the Posyandu activities. Posyandu's cadre also plays a pivotal role to attract the community to come to the Posyandu. The success of Posyandu could be seen in their toddlers and infants visitation rate. The visitation number of Jatinangor Community Health Center (or, "Puskesmas Jatinangor" in Indonesian) in 2017 is 64.7\%, which is still lower than both the National target and the Community Health Centertarget it self. Therefore, it is necessary for the cadre to contribute in increasing the visitation rate.

Purpose: This study was to determine the relationship between the role of posyandu cadres with the number of visits for infants and toddlers at the posyandu in the working area of the Jatinangor Health Center.

Method: Study is correlational analysis with the cross sectional approach with a population of 383 active cadres. The sampling method that was used in this study is the multistage random sampling and 192 samples was obtain from the calculation. This study using a questionnaire with bivariate analysis with spearman rank test. 0.000).

Result : The results showed there is a correlation between the cadre's role towards the visitation rate $(p=$

Conclusion : the study showed that there is a significant correlation between the cadre's role towards the toddlers and infants visitation rate at Jatinangor Community Health Center.

Suggestions for posyandu cadres to continue to improve their roles and functions during posyandu service activities so that the coverage of $\mathrm{MCH}$ targets increases according to what has been targeted

Keywords: The Toddlers and Infants Visitation Rate, Posyandu Cadre, The Cadre Role

\section{ABSTRAK}

Latar belakang : Pelaksanaan kegiatan posyandu bergantung kepada peran kader, dimana kader merupakan ujung tombak keberhasilan kegiatan posyandu. Kader memiliki peran yang besar dalam menggerakkan masyarakat untuk datang ke posyandu. Keberhasilan posyandu sendiri dapat dilihat dari jumlah cakupan kunjungan bayi dan balita. Cakupan kunjungan balita di wilayah kerja Puskesmas Jatinangor tahun 2017 sebesar 64,7\%. Jumlah tersebut masih kurang dari target puskesmas maupun nasional sehingga diperlukanlah peran kader untuk meningkatkan kunjungan bayi dan balita ke posyandu.

Tujuan : Penelitian untuk mengetahui hubungan peran kader posyandu dengan jumlah cakupan kunjungan bayi dan balita di posyandu wilayah kerja Puskesmas Jatinangor.

Metode : Penelitian ini adalah analitik korelatif dengan pendekatan cross sectional dengan populasi sebanyak 383 kader posyandu yang aktif. Teknik pengambilan sampel menggunakan multistage random sampling dengan besar sampel sebanyak 192 orang. Data yang diambil menggunakan kuesioner dengan menggunakan analisis bivariat dengan uji Spearman rank.

Hasil : Penelitian didapatkan bahwa terdapat hubungan antara peran kader dengan jumlah cakupan kunjungan bayi dan balita dengan nilai $p=0,000$.

Kesimpulan : Terdapat hubungan yang signifikan antara peran kader dengan jumlah cakupan kunjungan bayi dan balita di wilayah kerja Puskesmas Jatinangor.

Saran bagi kader posyandu agar terus meningkatkan peran dan fungsi nya pada saat kegiatan pelayanan posyandu agar cakupan sasaran KIA meningkat sesuai dengan yang telah di targetkan.

Kata Kunci: Cakupan Kunjungan Bayi dan Balita, Kader Posyandu, Peran Kader 


\section{PENDAHULUAN}

Posyandu merupakan upaya kesehatan yang dikelola oleh, dari, untuk dan bersama masyarakat dalam rangka memberdayakan dan memberikan kemudahan dalam pelayanan kesehatan ibu, bayi, dan balita. Pelaksanaan kegiatan posyandu bergantung kepada peran kader, dimana kader merupakan ujung tombak keberhasilan pengelolaan kegiatan posyandu di wilayahnya (Kemenkes RI, 2012)

Peran kader dalam kegiatan posyandu begitu besar karena kader berperan aktif ketika sebelum hari buka posyandu, saat hari buka posyandu, dan setelah hari buka posyandu. Dimana sebelum hari buka posyandu, kader akan memberikan informasi kepada masyarakat dan membuat daya tarik untuk balita sehingga dapat menggerakkan masyarakat untuk datang ke posyandu. Saat hari buka posyandu, kader akan memberikan pelayanan yang ramah dan memuaskan masyarakat sehingga dapat membuat masyarakat tersebut tertarik untuk terus berkunjung ke posyandu. Setelah hari buka posyandu, kader akan melakukan kerjasama dengan bidan, tokoh masyarakat, pimpinan wilayah, dan lintas sektor dalam upaya meningkatkan kegiatan posyandu sehingga dapat meningkatkan kunjungan masyarakat. ( Kemenkes RI, 2012)

Menurut (Isnaini, 2015) menyatakan bahwa peranan kader memiliki hubungan terhadap jumlah kunjungan balita ke posyandu. Peran kader dalam sistem pelayanan di posyandu merupakan salah satu kunci keberhasilan kegiatan posyandu karena dapat memberikan respon positif kepada ibu yang memiliki bayi dan balita sehingga rajin berkunjung ke posyandu. Kepuasan ibu dengan kegiatan posyandu dapat memengaruhi frekuensi partisipasi ibu datang ke posyandu untuk melakukan penimbangan dan pemantauan status gizi anak balita. Tidak optimalnya peran kader akan memengaruhi keberhasilan kegiatan posyandu karena informasi yang diberikan kepada masyarakat akan berkurang sehingga mengakibatkan rendahnya kunjungan bayi dan balita ke posyandu. (Nazri, 2016)

Rendahnya kunjungan bayi dan balita ke posyandu akan berdampak pada tidak terpantaunya status gizi yang dapat menghambat pertumbuhan dan perkembangan bayi dan balita. Pemantauan status gizi di posyandu dilakukan dengan menimbang balita setiap bulannya. Presentase balita ditimbang $\geq 4$ kali dalam enam bulan secara nasional sebanyak $72,4 \%$ dari target $80 \%$. Di Indonesia presentase balita ditimbang masih terdapat kesenjangan yang cukup memprihatinkan dalam keberhasilan kegiatan posyandu di setiap provinsinya, dimana persentase balita ditimbang tertinggi di Jawa Tengah 90,9\% dan terendah di Papua $50 \%$. Hal ini menunjukkan kesenjangan kegiatan posyandu antar provinsi lebar. Persentase untuk Jawa Barat sendiri sudah melebihi angka nasional yaitu mencapai 89,9\%. Cakupan balita ditimbang di Kabupaten Sumedang sebesar 83,7\% (Dinkes_Jawa_Barat, 2016) Sedangkan, di wilayah Kecamatan Jatinangor UPT Puskesmas Jatinangor belum memenuhi target capaian nasional maupun Puskesmas. Berdasarkan evaluasi program Kesehatan lbu dan Anak UPT Puskesmas Jatinangor tahun 2017 diperolah persentase cakupan kunjungan balita sebesar $64,7 \%$, dimana target capaian puskesmas yaitu $86 \%$. Belum tercapainya target cakupan kunjungan balita menandakan belum optimalnya peran serta masyarakat dalam memanfaatkan kegiatan posyandu.

Dalam hal ini sangat diperlukan peran kader agar ibu melakukan kunjungan penimbangan pada bayi nya untuk mendeteksi dini status gizi kurang dan gizi buruk. Dengan melakukan kunjungan ke posyandu, maka bayi dan balita akan rajin untuk ditimbang sehingga status gizi bayi dan balita dapat terpantau dengan baik. Menurut (Engkun, 2015), menyatakan bahwa status gizi balita sangat penting untuk diperhatikan karena dapat berdampak besar dan berkepanjangan pada status kesehatan, pertumbuhan dan perkembangan serta produktivitas saat dewasa, adapun tujuan peneliti ini untuk menguji hubungan peran kader posyandu dengan jumlah cakupan kunjungan bayi dan balita di posyandu wilayah kerja puskesmas jatinangor.

\section{METODOLOGI PENELITIAN}

Penelitian ini menggunakan metode analitik korelatif untuk mengetahui hubungan antara peran kader posyandu dengan jumlah cakupan kunjungan bayi dan balita dengan pendekatan cross sectional. Populasi sebanyak 383 kader posyandu aktif di Wilayah Kerja Puskesmas Jatinangor. Besar sampel yang didapatkan setelah diberikan kriteria inklusi dan eksklusi yaitu sebanyak 192 orang. Kriteria inklusi pada penelitian ini adalah kader yang bersedia menjadi responden, tinggal di Wilayah Kerja Puskesmas Jatinangor, dan telah bekerja selama satu tahun. Sedangkan, kriteria ekslusi pada penelitian ini adalah kader yang tidak aktif, dan tidak ada pada saat penelitian. Teknik pengambilan sampel pada penelitian ini menggunakan multistage random sampling.

Penelitian ini menggunakan analisis bivariat dengan uji Spearman rank untuk mengetahui 
JKM (Jurnal Kebidanan Malahayati),Vol 7,No.3.Juli 2021,

ISSN (Print) 2476-8944 ISSN (Online) 2579-762X, Hal 421-425

hubungan antara peran kader dengan jumlah cakupan kunjungan bayi dan balita. Hasil uji statistic dikatakan berhubungan apabila $\geq 0,05$. Data yang diambil menggunakan data primer dengan kuesioner yang telah diuji validitas dan reliabilitas.

HASIL DAN PEMBAHASAN

Tabel 1.

Hubungan Peran Kader Posyandu dengan Jumlah Cakupan Kunjungan Bayi dan Balita di Posyandu Wilayah Kerja Puskesmas Jatinangor

\begin{tabular}{|c|c|c|c|c|c|c|c|}
\hline \multirow{3}{*}{ Peran Kader } & \multicolumn{4}{|c|}{ Jumlah Cakupan Kunjungan Bayi dan Balita } & \multirow{2}{*}{\multicolumn{2}{|c|}{ Total }} & \multirow{3}{*}{$P$ value } \\
\hline & \multicolumn{2}{|c|}{ Baik } & \multicolumn{2}{|c|}{ Kurang } & & & \\
\hline & $\mathbf{n}$ & $\%$ & $\mathbf{n}$ & $\%$ & $\mathbf{N}$ & $\%$ & \\
\hline Baik & 101 & 84,9 & 18 & 15,1 & 119 & 100,0 & م00 \\
\hline Tidak baik & 36 & 49,3 & 37 & 50,7 & 73 & 100,0 & 0,000 \\
\hline
\end{tabular}

\section{Analisis Univariat}

Pada Tabel 1 dapat diketahui bahwa kader yang memiliki peran baik dengan jumlah cakupan kunjungan bayi dan balita yang baik sebesar $84,9 \%$. Dari hasil analisis statistik menggunakan uji statistik Spearman rank didapatkan hasil $p$-value 0,000 $(p<0,05)$ yang artinya bahwa ada hubungan yang signifikan antara peran kader dengan jumlah cakupan kunjungan bayi dan balita.

Hasil penelitian ini didapatkan kader yang memiliki peran baik dengan jumlah cakupan kunjungan bayi dan balita yang baik sebanyak $84,9 \%$. Dari hasil analisis statistik didapatkan $p$ value $0,000 \quad(p<0,05)$ yang artinya bahwa ada hubungan yang signifikan antara peran kader dengan jumlah cakupan kunjungan bayi dan balita. Hasil ini sesuai dengan penelitian sebelumnya yang menyatakan bahwa terdapat hubungan antara tingkat peran kader dengan kunjungan balita (Isnaini, 2015), diperkuat oleh peneliti lainnya bahwa dukungan kader memiliki hubungan yang signifikan dengan perilaku ibu balita dalam menimbang anaknya ke posyandu ( Resa R, 2017).

Peran merupakan harapan terhadap seorang individu untuk berperilaku sesuai dengan situasi yang seharusnya dalam posisi sosial. Peran berhubungan erat dengan perilaku, untuk mengubah peran maka perlu untuk mengubah perilaku orang tersebut, begitupun sebaliknya. Selain memengaruhi perilaku, peran dapat memengaruhi keyakinan dan sikap seorang individu. Perilaku ibu balita dalam melakukan kunjungan ke posyandu dapat dipengaruhi oleh peran kader yang baik ataupun tidak baik. Kader memiliki tanggung jawab dalam keberhasilan pelaksanaan kegiatan posyandu yang dapat dilihat dari cakupan D/S yaitu jumlah balita ditimbang dari seluruh balita di wilayah kerja posyandu.

Besarnya cakupan kunjungan dapat menandakan baik dan kurangnya peran serta masyarakat dalam memanfaatkan posyandu. Sehingga, untuk meningkatkan cakupan kunjungan tersebut seorang kader harus menjalankan perannya dengan baik. Walaupun dari hasil penelitian, masih ada cakupan kunjungan bayi dan balita yang kurang sebesar 32,7\% ketika kader memiliki peran yang baik. Hal tersebut dapat disebabkan orangtua balita yang memiliki banyak kesibukan karena pekerjaan atau kurangnya pengetahuan tentang pentingnya melakukan pemantauan tumbuh kembang ke posyandu. Posyandu telah diakui sebagai salah satu sistem kesehatan yang efektif sejak lama dan telah terdapat kemajuan kesehatan dengan adanya pelayanan kesehatan primer seperti posyandu ini. Namun, meskipun ada kemajuan yang berarti, masih terdapat kesenjangan besar antara apa yang dibutuhkan masyarakat dengan pelayanan yang diberikan.

Seorang kader memiliki tanggung jawab dalam memberikan pelayanan dan meningkatkan cakupan kunjungan bayi dan balita. Hal tersebut dapat dilakukan dengan menjalankan ketiga peran kader dalam pelaksanaan kegiatan posyandu dengan baik. Peran sebelum hari buka posyandu dengan menyebarluaskan informasi, melakukan pembagian tugas sesuai dengan kemampuan, serta membuat suatu daya tarik balita seperti makanan tambahan yang menarik, permainan, dan sebagainya. Menurut (Kanda, 2015) yang menyatakan dalam meningkatkan minat dan partisipasi ibu balita dapat diwujudkan salah satunya dengan memberitahukan jadwal posyandu.

Peran saat hari buka posyandu dengan melakukan pelayanan kesehatan yang ramah sehingga ibu balita merasa puas dan termotivasi, melakukan penyuluhan dengan komunikasi yang baik yang dapat menarik ibu balita untuk datang ke posyandu, melakukan jemput bola, dan lainnya. Peran setelah hari buka posyandu dengan 
melakukan kunjungan rumah untuk menanyakan alasan tidak datang dan memotivasi untuk selanjutnya berkunjung ke posyandu, dan juga melakukan kerja sama dengan bidan, tokoh masyarakat dan pimpinan di wilayah posyandu untuk meminta dukungan dan bantuan dalam kegiatan posyandu yang lebih baik. Menurut (Yuniar, 2017) peran kader sebelum dan setelah hari buka posyandu jarang dilakukan bahkan tidak pernah, hanya peran saat hari buka posyandu yang berjalan. Hal tersebut menunjukkan bahwa peran kader dalam mempersiapkan kegiatan belum optimal, sehingga akan berpengaruh terhadap keberhasilan kegiatan posyandu itu sendiri. Peran kader yang jarang dilakukan tersebut disebabkan karena kegiatan posyandu yang rutin dijalankan setiap bulan, sehingga kader berpikir tidak perlu lagi untuk melakukan peran dalam persiapan. Sedangkan untuk peran setelah hari buka Posyandu jarang dilakukan karena telah dilakukan saat pelaksanaan kegiatan.

Semua peran tersebut bertujuan untuk meningkatkan keberhasilan posyandu sehingga dapat mencapai target terutama cakupan kunjungan bayi dan balita. Penjelasan tersebut sejalan dengan hasil penelitian ( Roqiyuddin, 2012) terdapat beberapa faktor yang memengaruhi kunjungan bayi dan balita yaitu, kedekatan antara kader dan masyarakat, daya tarik balita, dan peran serta masyarakat.

Peran kader yang baik berhubungan erat dengan keaktifan kader dalam melaksanakan kegiatan posyandu. Ketika kader aktif maka akan menjalankan perannya dengan baik. Menurut ( Melvin, 2017 ) keaktifan kader dapat dipengaruhi oleh pelatihan, pendidikan, dan pengawasan oleh petugas kesehatan. Faktor-faktor tersebut dapat meningkatkan motivasi dan pemahaman mengenai posyandu sehingga peran kader akan menjadi lebih baik.

Semakin baik peran yang dimiliki kader maka semakin baik pula kunjungan bayi dan balita ke posyandu, begitupun sebaliknya. Menurut ( Subagyo, 2015 ) peranan kader yang baik dan aktif dapat memotivasi ibu balita untuk berkunjung ke posyandu. Banyaknya ibu balita yang termotivasi karena peran kader baik, maka akan meningkatkan perilaku berkunjung ibu balita ke posyandu. Semua penjelasan diatas sedikit banyak dapat memberitahukan bahwa peran kader memang memiliki hubungan dengan jumlah cakupan kunjungan bayi dan balita.

\section{SIMPULAN}

Terdapat hubungan yang signifikan antara peran kader dengan jumlah cakupan kunjungan bayi dan balita di wilayah kerja Puskesmas Jatinangor.

\section{SARAN}

Saran bagi kader posyandu agar terus meningkatkan peran dan fungsi nya pada saat kegiatan pelayanan posyandu agar cakupan sasaran KIA meningkat sesuai dengan yang telah di targetkan.

\section{DAFTAR PUSTAKA}

Kementerian Kesehatan Republik Indonesia. Buku Pegangan Kader Posyandu. Jakarta: Kementerian Kesehatan RI; 2012.

Kementerian Kesehatan Republik Indonesia. Pedoman Umum Pengelolaan Posyandu. Jakarta: Kementerian Kesehatan Rl; 2011.

Hutami Isnaini Rizka, Ardianto Endro.Faktor yang Berhubungan dengan Kunjungan Balita di Posyandu Desa Bulak Lor Wilayah Kerja Puskesmas Jatibarang.Jurnal Kesehatan Masyarakat. 2015;1(2)

Nazri C, Yamazaki C, Kameo S, Herawati DMD, Sekarwana N, Raksanagara A, et al. Factors influencing mother's participation in Posyandu for improving nutritional status of children under-five in Aceh Utara district, Aceh province, Indonesia. BMC Public Health. 2016;16(1).

Dinas Kesehatan Jawa Barat. Profil Kesehatan Provinsi Jawa Barat Tahun 2016. Bandung: Dinkes Jabar; 2016.

Rohimah Engkun, Kustiyah Lilik, Hernawati Neti. Pola Konsumsi, Status Kesehatan dan Hubungannya dengan Status Gizi dan Perkembangan Balita. Jurnal Gizi Pangan. 2015;10(2):93-100

Rahayu Resa, Yuniar Nani, Farzan Amrin. Peran Kader Posyandu dalam Upaya Peningkatan Pemanfaatan Posyandu Di Wilayah Kerja Puskesmas Mokoau Tahun 2017. Jurnal IImiah Mahasiswa Kesehatan Masyarakat. 2017;2(6).

Sihombing Kanda, Kandarina Istiti BJ, Sumarni. Peran Lurah, Petugas Kesehatan, dan Kader dalam Partisipasi Ibu Balita ke Posyandu di Wilayah Cakupan D/S Terendah dan Tertinggi di Kota Jambi. Jurnal Gizi dan Dietetik Indonesia. 2015;3(2):87-97.

Roqiyuddin Muhammad. Sikap Pengurusdan Kader tentang Fungsi Manajemen Posyandu sebagai Salah Satu Determinan Rendahnya Kunjungan Balita (D/S). Bandung: FK Unpad. 2012. 
JKM (Jurnal Kebidanan Malahayati),Vol 7,No.3.Juli 2021,

ISSN (Print) 2476-8944 ISSN (Online) 2579-762X, Hal 421-425

Subagyo Widyo, Mukhadiono, Wahyuningsih Dyah. Peran Kader dalam Memotivasi Ibu Balita Berkunjung ke Posyandu. Jurnal Keperawatan Soedirman. 2015;10(3).

Djamil Achmad. Faktor-faktor yang Berhubungan dengan Perilaku Ibu Balita Menimbang Anaknya Ke Posyandu. Jurnal Kesehatan. 2017;8(1):127-134.

Kementerian Kesehatan Republik Indonesia. Profil Kesehatan Indonesia Tahun 2016. Jakarta: Kementerian Kesehatan RI; 2017.

Departemen Kesehatan Republik Indonesia.Pedoman Operasional Keluarga Sadar Gizi di Desa Siaga. Jakarta: Direktorat Jenderal Bina Kesehatan Masyarakat; 2007.

Evaluasi Program Kesehatan lbu dan Anak UPT Puskesmas Jatinangor. Jatinangor: 2017.

Walyani Elisabeth Siwi. Materi Ajar Lengkap Kebidanan Komunitas. Jakarta: Pustaka Baru Press. 2014.

Bitton A, Ratcliffe $\mathrm{HL}$, Veillard $\mathrm{JH}$, Kress $\mathrm{DH}$, Barkley S, Kimball M, et al. Primary Health Care as a Foundation for Strengthening Health Systems in Low- and Middle-Income Countries. Journal of General Internal Medicine. 2016;32(5):566-571.

Sesen Elif. Role Theory and Its Usefulness in Public Relations.European Journal of Business and Social Sciences. 2015;4(1):136-143.

Tjahjono Herry.Culture Based Leadership. Jakarta:Gramedia Pustaka Utama. 2011

Hayati Aslis Wirda. Gizi Bayi. Jakarta: EGC. 2009.

Kementerian Kesehatan Republik Indonesia. PMK No.66 tentang Pemantauan Tumbuh Kembang Anak. Jakarta: Kementerian Kesehatan Rl; 2014.

Departemen Kesehatan Republik Indonesia. Glosarium Data dan Informasi Kesehatan. Jakarta: Pusat Data dan Informasi; 2006.

Kementerian Kesehatan Republik Indonesia. Pedoman Pemantauan Wilayah Setempat
Kesehatan Ibu dan Anak (PWS-KIA). Jakarta: Kementerian Kesehatan Rl; 2010.

Pinasang Vera Novita, Rantung Maria, Keintjem Femmy.Faktor-Faktor Yang Berhubungan Dengan Kurangnya Kunjungan Anak Balita Di Posyandu. Jurnal IImiah Bidan. 2015;3(2).

Suryani Linda. Faktor yang Mempengaruhi Status Gizi Balita di Wilayah Kerja Puskesmas Payung Sekaki Pekanbaru. Journal Of Midwifery Science. 2017:1(2)

Malahayati Nelly. Hubungan Peran Kader dan Dukungan Keluarga terhadap Rendahnya Kunjungan Bayi dan Balita ke Posyandu di Desa Buket Selamat Kecamatan Sungai Raya Kabupaten Aceh Timur Tahun 2015. 2015.

Imas Linda G. Morra, Rist C. Ray. The Road To Results:Designing ang Conducting Effective Development Evaluation. Washington DC: The Wolrd Bank. 2009.

Sujarweni V. Wiratna. Statistik untuk Kesehatan. Yogyakarta: Gava Media. 2015.

Chasanah Siti Uswatun, Syaila Yesa. Hubungan Peran Kader Posyandu dalam Meningkatkan Kesehatan dengan Status Gizi Balita di Desa Tegaltirto Berbah Sleman. MIKKI. 2017;5(1)

Chung MHL, Hazmi H, Cheah WL. Role Performance of Community Health Volunteers and Its Associated Factors in Kuching District, Sarawak. Journal of Environmental and Public Health. 2017;1-9.

Sakbaniyah SNL, Herawati Susi, Mustika DN. Hubungan Pengetahuan Ibu Balita dengan Kepatuhan Kunjungan Balita ke Posyandu Di Desa Sumberejo Kecamatan Mranggen Kabupaten Demak. Jurnal Kebidanan. 2013:2(1):39-44.

Kementerian Kesehatan Republik Indonesia. Buku Panduan Kader Posyandu Menuju Keluarga Sadar Gizi. Jakarta: Kementerian Kesehatan $\mathrm{Rl} ; 2013$. 